\title{
Research on Motivation of Corporate Social Responsibility Based on Game Theory
}

\author{
ZHAO Gongmin \\ North University of China, Taiyuan, China
}

\begin{abstract}
The negative externalities of businesses brought serious social and environmental problems. Based on externality theory and game theory, the author in-depth analyzes intrinsic motivation of corporate social responsibility, and points out that corporate social responsibility will increase production costs, so companies will not take the initiative to raise the level of social responsibility. Through the analysis of corporate social responsibility profits, the paper reveals that if the government lack reasonable system to regulate corporate behavior, then the firm, pursuiting maximizing profit, will choose the Nash equilibrium of consumpting public resources, and not take the initiative to fulfill their social responsibility to seek the Pareto equilibrium of the whole regional optimal, which results in high output and low returns. The research finds that the government should strengthen the publicity of corporate social responsibility, privatization of corporate social responsibility benefits and establishment of corporate social responsibility system and other means to guide and standardize the corporate social responsibility.
\end{abstract}

Keywords: corporate social responsibility, externalities, static game, Nash equilibrium

\section{Introduction}

Indulged in the great achievements of economic construction, we should have a clear understanding that we have paid a huge price: only $14 \%$ of the land is covered by forest; China accounted for more than half of the world's 10 most polluted cities; and 700 million people are drinking with contaminated water (LU, 2009). Peter Drucker pointed out that a healthy business and sick society could not coexist. If the business only seeks to maximize their own interests, and not fulfill their social responsibility to reduce the negative externalities they brought about, which will inevitably lead to imbalance in the distribution of corporate interests and social benefits. Enterprise, a product of society, provides products and services for the community, so it must reflect the moral and legal value of the community when pursuing the economic interest.

\section{Cost of Corporate Social Responsibility}

Assume that the corporate operating activities bring about negative externalities, and the fulfillment of corporate's social responsibility could reduce the negative externalities. However, based on the maximization of their own interests, enterprises have no incentive to compensate for the external social costs when making

ZHAO Gongmin, Master, Professor, School of Economics and Management, North University of China.

Correspondence concerning this article should be addressed to ZHAO Gongmin, School of Economics and Management, North University of China, Taiyuan, Shanxi, 030051, China. E-mail: zhaogm1@nuc.edu.cn. 
production decisions. In order to simplify model, we assume:

- Enterprises are in competitive markets, all have the same size and technology, also have the same problems of negative externalities;

- The proportion of production function is fixed, and the only way to reduce the negative externalities is to fulfill their social responsibilities;

- Negative externalities are arising with production activities.

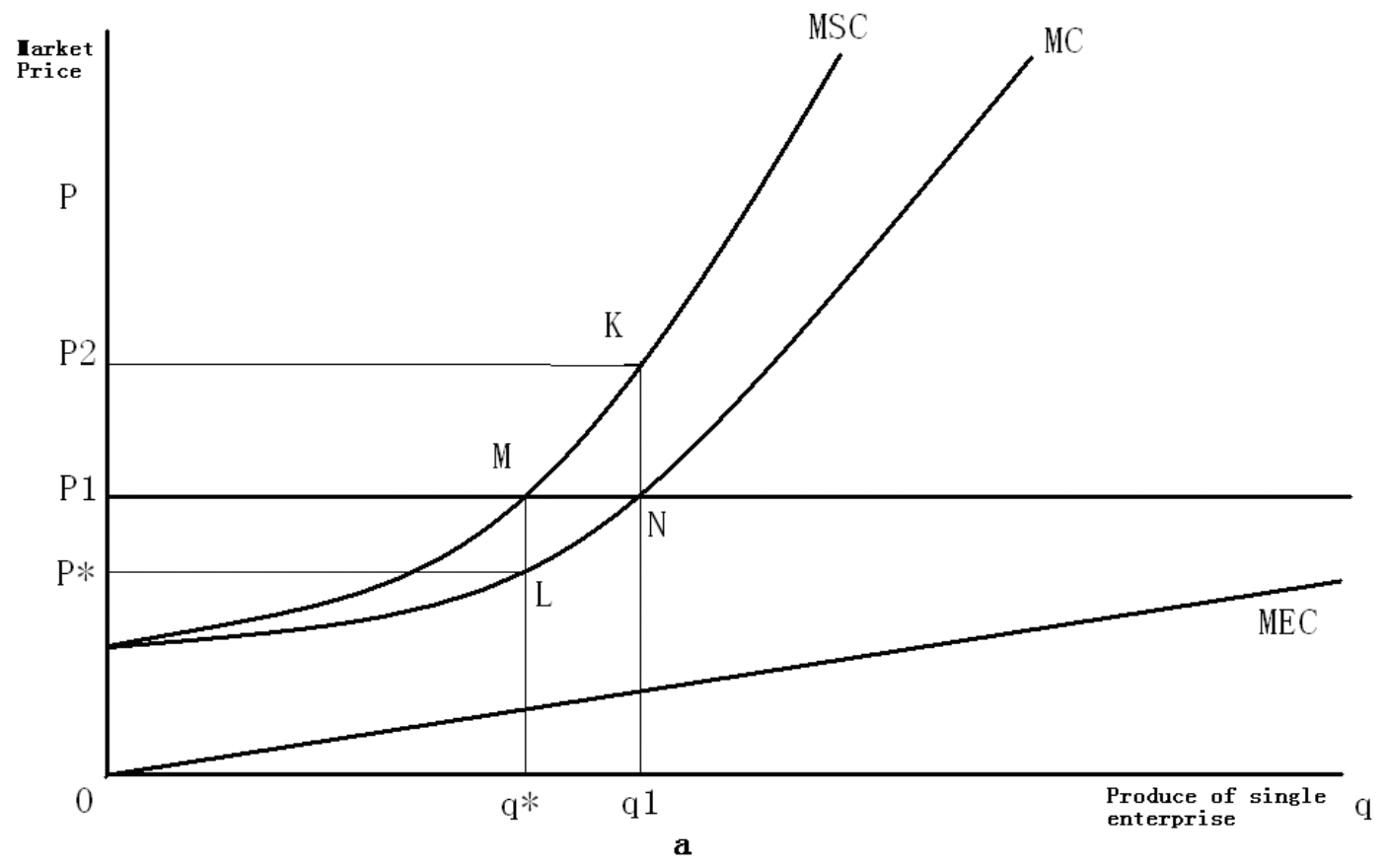

Figure 1. Production decision of single enterprise.

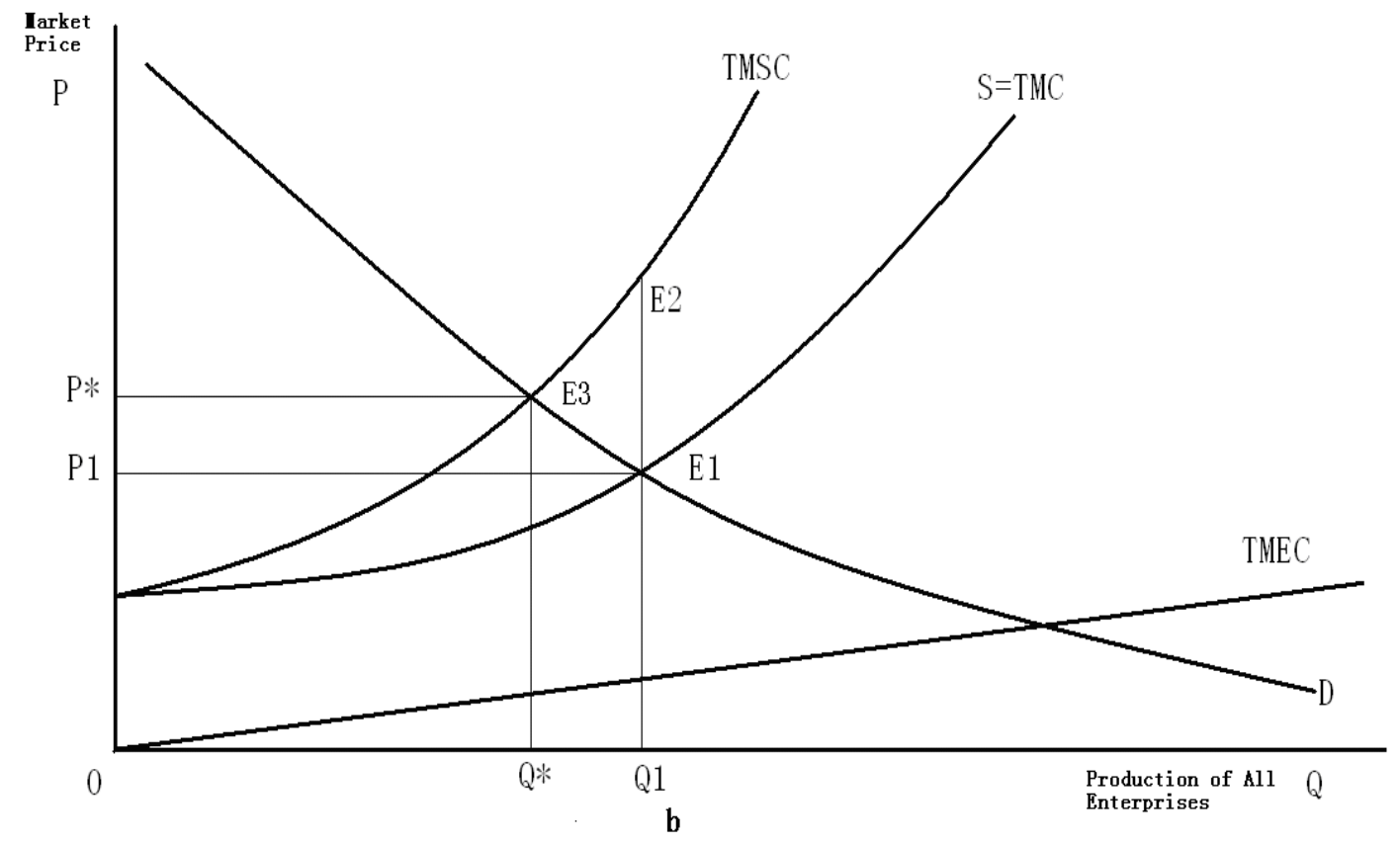

Figure 2. Production cost of all enterprises. 
The market price of their products is $P_{1}$, which was determined by the intersection of the supply and demand curves in Figure 2. In Figure 1, $M C$ curve represents the marginal cost of a typical enterprise. When the production is $q_{1}$, the profit maximizes, then $P=M C=M R$ ( $P$ is given). For the marginal external cost curve ( $M E C$ curve), the social costs changes with the production of enterprises. If the production is greater, negative externalities are more serious and the social cost was much higher, therefore, MEC curve slopes upward (Pindyck, 2006).

From perspective of society, enterprises yield too high. The level of output is most effective when the price $P=M S C$, is $M C$ plus MEC. To achieve this, businesses are required to fulfill their social responsibility and assume the cost of $M E C$, then $M C$ curve moves closer to the $M S C$ curve and achieves a balanced at point $M$, while market prices remain at $P_{1}$, and the enterprise's production dropped at $q^{*}$.

\section{Analysis of Fulfillment of Corporate Social Responsibility Based on Game Theory}

\section{Rational Choice of Individual}

We use game theory to further analyze intrinsic motivation of corporate social responsibility.

Assume that rational behavior of individuals within the region is $i(i=1,2, \ldots \ldots, n)$, their level of corporate social responsibility is $r_{i}$ (such as increasing employee benefits, improving working conditions, public welfare, and energy conservation, etc.), total level of corporate social responsibility of $n$ enterprises within the region were $R$, and $R=\sum_{i=1}^{n} r_{i}$. The price and amount of other items (except public resources) are $O_{p}$ and $l_{i}$ respectively when typical enterprise $i$ purchasing, the unit cost of social responsibility is $C_{p}$, and the budget income is $\omega_{i}$. The utility that enterprise $i$ fulfills $r_{i}$ units of social responsibility and purchase $l_{i}$ units of other goods is $U_{i}=U_{i}(l, r)$, and the marginal utility and marginal rate of substitution diminishing, $\frac{\partial^{2} U_{i}}{\partial l_{i}^{2}}<0, \frac{\partial^{2} U_{i}}{\partial r^{2}}<0$, therefore $M R S_{r l_{i}}=\frac{\partial U_{i} / \partial r}{\partial U_{i} / \partial l_{i}}$ is a decreasing function of $r$.

If starting from the maximization of their own interests, the individual optimization problem of performing social responsibility of the $n$ enterprises within the region will become the complete information static game problem of the enterprises:

$$
\begin{array}{r}
\operatorname{Max}_{r_{i}, l_{i}}=U_{i}\left(l_{i}, r_{i}\right) \\
\text { s.t. }\left\{\begin{array}{c}
\omega_{i}=O_{p} l_{i}+C_{p} r_{i} \\
R=\sum_{i=1}^{n} r_{i}
\end{array}\right.
\end{array}
$$

Using Lagrangian function to figure out its optimization problem, the first-order conditions are:

$$
\left\{\begin{array}{l}
\frac{\partial U_{i}}{\partial r}-\lambda C_{p}=0 \\
\frac{\partial U_{i}}{\partial l_{i}}-\lambda O_{p}=0
\end{array}(i=1,2, \ldots \ldots, n)\right.
$$

Therefore, we get:

$$
M R S_{r_{i}}=\frac{\partial U_{i} / \partial r}{\partial U_{i} / \partial l_{i}}=\frac{C_{p}}{O_{p}} \quad(i=1,2, \ldots \ldots ., n)
$$

Equation (3) shows that in the game of performing social responsibility of the enterprises, if every company focuses on its own interests instead of fulfilling their social responsibilities, then their Nash equilibrium 
$\left\{\left(r_{1}^{*}, r_{2}^{*}, \ldots \ldots, r_{n}^{*}\right), R^{*}=\sum_{i=1}^{n} r_{i}^{*}\right\}$ satisfies equation (3):

$$
\operatorname{MRS}_{r l_{i}}\left(r^{*}\right)=\frac{C_{p}}{O_{p}} \quad(i=1,2, \ldots \ldots, n)
$$

\section{The Best Overall Interest of Region}

If these enterprises examine this issue from a holistic approach, the Pareto optimal level of social responsibility is as follows:

$$
\left\{\begin{array}{c}
M a x U=\sum_{i=1}^{n} \xi_{i} U_{i} \\
\text { s.t. } \sum_{i=1}^{n} \omega_{i}=O_{p} \sum_{i=1}^{n} l_{i}+C_{p} r
\end{array}\right.
$$

where $\xi_{i}$ are weights, and $\xi_{i} \geq 0, \sum_{i=1}^{n} \xi_{i}=1$, when status of the enterprise are equal, $\xi_{i}=\frac{1}{n}(i=1,2, \ldots \ldots, n)$. When the status are different, enterprises in higher status correspond to larger weights; and vice versa. First-order conditions are:

$$
\left\{\begin{array}{c}
\sum \xi_{i} \frac{\partial U_{i}}{\partial r}-\lambda C_{p}=0 \\
\xi_{i} \frac{\partial U_{i}}{\partial l_{i}}-\lambda O_{p}=0
\end{array} \quad(i=1,2, \ldots \ldots, n)\right.
$$

Eliminating $\xi_{i}$ and $\lambda$, then we get the satisfaction of Pareto optimum as follows:

$$
\begin{gathered}
\sum_{j \neq i} \frac{\partial U_{i} / \partial r}{\partial U_{i} / \partial l_{i}}=\frac{C_{p}}{O_{p}} \\
\frac{\partial U_{i} / \partial r}{\partial U_{i} / \partial l_{i}}=\frac{C_{p}}{O_{p}}-\sum_{j \neq i} \frac{\partial U_{j} / \partial r}{\partial U_{j} / \partial l_{j}}
\end{gathered}
$$

Combine equation (3) with equation (8):

$$
\operatorname{MRS}_{r l_{i}}\left(r^{* *}\right)=\frac{C_{p}}{O_{p}}-\sum_{j \neq i} \frac{\partial U_{j} / \partial r}{\partial U_{j} / \partial l_{j}}<\frac{C_{p}}{O_{p}}=M R S_{r l_{i}}\left(r^{*}\right)
$$

By equation (9) and $M R S_{r l_{i}}=\frac{\partial U_{i} / \partial r}{\partial U_{i} / \partial l_{i}}$, a decreasing function of $r$, we can figure out $r^{* *}>r^{*}$, which means that these companies' Pareto optimal level of social responsibility when considering from the interests of the whole region, is much higher than their Nash equilibrium level of social responsibility when considering the individual interests. This shows that enterprises can not fulfill corporate social responsibility voluntarily, and this undesirable phenomenon will be widespread in the region, which brought about serious effects for the citizens and the environment (Dasgupta \& Heal, 1974).

\section{The Relationship Between Corporate Social Responsibility and Profits}

Fulfillment of corporate social responsibility could cause production costs rising, profit margins shrinking and the overall profits declining (Dasgupta, Mody, Roy, \& Wheeler, 2001). Therefore, we make an assumption as follows:

H: Corporate social responsibility has a positive impact on production costs and has a negative impact on corporate profit.

We assume the negative externalities of enterprises as the corporate consumption of public resources, and 
we note the corporate consumption of public resources as $\mathrm{H}$ (with a non-exclusive nature). If government has not took regulations to regulate this, we assume the consumption of public resources $\mathrm{H}$ of rational behavior individuals (we note these individuals as $i, i=1,2,3 \ldots . n, i$ presents enterprise) within the region as $k_{i}$, such as the exploitation of mineral resources, water use, discharge of sewage and river emissions etc.. $k_{i}$ is the output of a single enterprise, and the higher the output is, the greater the consumption(demand) of public resources is. The total consumption of public resources of these enterprises within the region is $K, K=\sum_{i=1}^{n} k_{i}$, in which $K$ presents these enterprise's total output. We assume that these enterprises have the same technology and size. After the public resources $H$ have been consumed $K$ units (productions are units units). For each enterprise, the average use value and the average acquisition costs of each unit public resources are the same, and we note them as $V(K)$ and $C(K)$ respectively. $V(K)$ diminishes with $K$ increasing and $C(K)$ increases with $K$ increasing, for example, the utility value of water diminishes with discharge increasing, while the acquisition costs (control costs) increase along with emissions increasing which can be written as $V^{\prime}(K) \leq 0 V^{\prime \prime}(K) \leq 0$ and $C^{\prime}(K) \geq 0 C^{\prime \prime}(K) \geq 0$. At this time, the profit $\pi_{i}$ of each enterprise $i$ after consumes $k_{i}$ units public resources (productions are $k_{i}$ units) is as follows:

$$
\pi_{i}=k_{i}[V(K)-C(K)]
$$

\section{Overall Pareto Optimum}

Viewing from the overall interests of the region, the Pareto optimization of these $n$ enterprises is:

$$
\operatorname{Max} \underset{\{K\}}{\pi}=K[V(K)-C(K)]
$$

The first order optimized conditions of equation (11) and Pareto optimal profit and less values are:

$$
\left\{\begin{array}{c}
V\left(K_{1}\right)-C\left(K_{1}\right)+K_{1} \times\left[V^{\prime}\left(K_{1}\right)-C^{\prime}\left(K_{1}\right)\right]=0 \\
\pi_{1}=K_{1} \times\left[V\left(K_{1}\right)-C\left(K_{1}\right)\right]
\end{array}\right.
$$

\section{The Maximization of Individual Interest}

If the enterprises consider from maximization of their own interests, and they have no incentive to compensate for the social and environmental external costs, then the optimized problem that these enterprises consumed public resources within the region will be transformed into complete information static game problem:

$$
\left\{\begin{array}{l}
\operatorname{Max}_{i}=k_{i}[V(K)-C(K)] \\
\text { s.t.K }=\sum_{i=1}^{n} k_{i}(i=1,2,3 \ldots . . n)
\end{array}\right.
$$

The first-order conditions of $\pi_{i}$ maximized is $\frac{\alpha \pi_{i}}{\alpha k_{i}}=0$, which means that the best consumption $k_{i 2}$ of rational behavior individual should satisfy the following conditions:

Adding these first-order conditions, we have:

$$
V(K)-C(K)+k_{i} \times\left[V^{\prime}(K)-C^{\prime}(K)\right]=0(i=1,2,3 \ldots \ldots . n)
$$

$$
\begin{aligned}
& \left\{\begin{array}{c}
n \times\left[V\left(K_{2}\right)-C\left(K_{2}\right)\right]+K_{2} \times\left[V^{\prime}\left(K_{2}\right)-C^{\prime}\left(K_{2}\right)\right]=0 \\
K_{2}=\sum_{i=1}^{n} k_{i 2}
\end{array}\right. \\
& \left\{V\left(K_{2}\right)-C\left(K_{2}\right)+\frac{K_{2} \times\left[V^{\prime}\left(K_{2}\right)-C^{\prime}\left(K_{2}\right)\right]}{n}=0\right. \\
& \pi_{2}=\sum_{i=1}^{n} \pi_{i 2}=K_{2} \times\left[V\left(K_{2}\right)-C\left(K_{2}\right)\right]
\end{aligned}
$$




\section{Comprehensive Comparison}

Comparing $K_{1}$ and $K_{2}$, we assume $K_{1} \geq K_{2}$.

Because of $\quad V^{\prime}(K) \leq 0 \quad V^{\prime \prime}(K) \leq 0 \quad$ and $\quad C^{\prime}(K) \geq 0 \quad C^{\prime \prime}(K) \geq 0 \quad$, therefore $\quad V^{\prime}(K)-C^{\prime}(K) \leq 0 \quad$ and $V^{\prime \prime}(K)-C^{\prime \prime}(K) \leq 0, V(K)-C(K)$ diminish with $K$ increasing, and combining with equation (15), we get:

$$
0<V\left(K_{1}\right)-C\left(K_{1}\right) \leq V\left(K_{2}\right)-C\left(K_{2}\right)=-\frac{K_{2} \times\left[V^{\prime}\left(K_{2}\right)-C^{\prime}\left(K_{2}\right)\right]}{n}
$$

According to equation (12), we have:

$$
V\left(K_{1}\right)-C\left(K_{1}\right)=-K_{1} \times\left[V^{\prime}\left(K_{1}\right)-C^{\prime}\left(K_{1}\right)\right]
$$

Combining equation (17) and equation (18), we get:

$$
\begin{aligned}
0 & \geq K_{1} \times\left[V^{\prime}\left(K_{2}\right)-C^{\prime}\left(K_{2}\right)\right] \geq K_{1} \times\left[V^{\prime}\left(K_{1}\right)-C^{\prime}\left(K_{1}\right)\right] \\
\geq & \frac{K_{2} \times\left[V^{\prime}\left(K_{2}\right)-C^{\prime}\left(K_{2}\right)\right]}{n}>K_{2} \times\left[V^{\prime}\left(K_{2}\right)-C^{\prime}\left(K_{2}\right)\right]
\end{aligned}
$$

Because $V^{\prime}\left(K_{2}\right)-C^{\prime}\left(K_{2}\right)<0$, we get $K_{1}<K_{2}$, which is contradict to the assumption $K_{1} \geq K_{2}$.

So the result is $K_{1}<K_{2}$, which means that the production when the enterprises fulfill corporate social responsibility is lower than that of enterprises without corporate social responsibility.

Due to $K_{1}<K_{2}, \pi^{\prime}\left(K_{1}\right)=0$ and $\pi^{\prime}<0$, we can easily figure out that function $\pi=K \times[V(K)-C(K)]$ is a decreasing function when $K$ in $\left[K_{1},+\infty\right)$. Then, $\pi_{1}=K_{1} \times\left[V\left(K_{1}\right)-C\left(K_{1}\right)\right]>\pi_{2}=K_{2} \times\left[V\left(K_{2}\right)-C\left(K_{2}\right)\right]$ which means the profits after fulfilling corporate social responsibility is greater than these of before.

\section{Conclusions and Recommendations}

Without fulfilling their social responsibilities, enterprises pursuing profit-maximization make private marginal cost lower than the marginal social cost and the output is too high, which will cause vicious competition among enterprises in the long-term and does not conducive to the development of the industry. On the other hand, it will bring about serious negative externalities, such as ecological degradation, the widening gap between the rich and the poor, causing imbalance of stakeholders' interests and disharmony of the community. The level of performing social responsibility is generally low, and the consumption of public resources is excess. If enterprises can take the initiative to fulfill corporate social responsibility and reduce the production, the profits will be higher than non-performance of social responsibility. Therefore, as an enterprise, profit-maximization is not the unique goal, it also should take full account of the interests of external stakeholders and society in business activities to fulfill its social responsibility.

\section{Governmental Encouragement Strategies for Performing Social Responsibility of Enterprise}

As a supervisor and service authority in the market competition environment, the government should apply macroeconomic measures, and establish regulations and systems effectively to guide enterprises to perform their social responsibilities based on the profits of them, the specific measures as follows:

(1) Strengthen publication and encouragement, and enhance the consciousness of social responsibility. It is obligatory for government to educate and train the enterprises in order to improve awareness of corporate social responsibility, and to promote social responsibility activities to the community and reduce the procurement of products produced by enterprises ignoring social responsibility. For example, for polluting enterprises, government should intensify the efforts of supervision, carry out environmental monitoring and appraisal, past green labels on their products to encourage consumers to give priority to purchasing such products, and strive to 
form an atmosphere of praising "green product" in the community (JIANG \& GU, 2008). Thus, enterprises with high environmental protection investment will also receive a higher return, and they will have an intrinsic motivation to improve their level of social responsibility;

(2) The government should make profits of corporate social responsibility privatized. Enterprises' performance of social responsibility has a positive impact on consumers, investors and employees, which improves the reputation of the enterprise, improves labor productivity, and potentially increases corporate profits. Through corporate social responsibility strategies, enterprises achieve products differentiation. Consumers are more willing to buy products that contain elements of social responsibility. Because of fulfillment of corporate social responsibility, enterprise could won the support of governments, communities and other stakeholders, and the government will favor them when formulating and implementing policies, to support the development of enterprises. The communities purchase their products to repay them, which results in a broader development space for enterprises;

(3) The government should administrate enterprises by regulations. Because business's goals and objectives of stakeholders are inconsistent, even if the norms of corporate behavior were more perfect, and that "there are policies and we have measures" is still existing and implements tend to lag behind. Because of the cost of penalty is low, many companies violate it knowingly, which, to some extent, encourages many enterprises disregard for social responsibility. To solve this problem, the government must modify the behavior of enterprises through legal means, enforce enterprises to fulfill a series of legal corporate social responsibility and control the forbidden behaviors, and establish effective monitoring mechanisms. Meanwhile, the government should speed up the establishment of the new system (SUN, 2009).

\section{Strategies of Corporate Social Responsibility}

Enterprises should implement strategies of corporate social responsibility. Enterprises should actively respond to the international standards of social responsibility, bring social responsibility into business development strategies. They should regard corporate social responsibility as an effective way to enhance the competitiveness of enterprises and to achieve a win-win situation of social development and enterprise development. In corporate social responsibility management, enterprises must choose realistic strategies according to the actual inside and outside situation. First, enterprises should regulate their own business ideas and marketing behaviors from the perspective of business ethics, establishing specific social responsibility goals in different stages of development of enterprise. Second, enterprises should establish ethical marketing concept, enhance awareness of corporate social responsibility. In the marketing process, enterprises not only need to properly handle the relationship between customers and enterprises in the marketing process, but also handle the shared interests between enterprises and other stakeholders (YANG, 2008). It should pay great attention on the role of ethics in business decisions, to establish ethical enterprise.

Enterprises should establish and improve the system of corporate social responsibility. Enterprises should adhere to the business philosophy of society-important and people-oriented, treat their staff friendly, protect the interests of employees, and establish harmonious labor relations. Enterprises should strictly follow the existing laws and regulations in China and international conventions to regulate their own behavior, continuously improve employee benefits, and improve work environment for employees. It should strengthen environmental-protection 
awareness and realize synergy effect of economic efficiency, social and ecological benefits.

\section{Limitation of the Research}

In this study, the model was assumed in a competitive market. But in reality, there are many companies in a competing-monopoly or oligopoly market, so the analyses of their marginal cost, revenue and marginal social cost are different. When the government using legal means to conduct corporate social responsibility, due to the law can't exhaustively cover corporate codes of conduct, and there are loopholes and lag problems in the law itself, the government is difficult to effectively monitor the acts of corporate social responsibility, therefore, the role of government policy will be greatly reduced.

\section{References}

Dasgupta, P. S., \& Heal, G. (1974). The optimal depletion of exhaustible resourees. Eeonomies of Exhaustible Resourees.

Dasgupta, S., Mody, A., Roy, S., \& Wheeler, D. (2001). Environmental regulation and development: Aeross-eountry empirieal analysis. Oxford Development Studies, 29, 273-187.

JIANG, Q. J., \& GU, Q. L. (2008). Corporate social responsibility and corporate strategic choice. Shanghai: Shanghai People’s Publishing House, 2, 196.

LU, F. Y. (2009, September). Evolutionary analysis of environmental pollution based on game theory. Systems Engineering Theory and Practice, 53-57.

Pindyck, R. (2006). Microeconomics (4th ed.). Beijing: China Renmin University Press, 1, 561-563.

SUN, A. (2009, May). Policy tools for environmental externalities managemen. Yunnan: Yunnan Social Science, 94-97.

YANG, F. J. (2008, September). Analysis of environmental pollution from an economic view and game theory. Productivity Research, 18, 32-37. 